\title{
Leydig cell function in mice lacking connexin43
}

\author{
Caroline N Kahiri ${ }^{1,2,3,5}$, M Wahid Khalil ${ }^{4}$, Francis Tekpetey ${ }^{1,2}$ and Gerald M Kidder ${ }^{1,2,3,5}$ \\ Departments of ${ }^{1}$ Physiology and Pharmacology, ${ }^{2}$ Obstetrics and Gynaecology, ${ }^{3}$ Paediatrics, ${ }^{4}$ Medicine, The \\ University of Western Ontario, London, Ontario, Canada N6A 5C1 and ${ }^{5}$ Children's Health Research Institute, 800 \\ Commissioners Road East, London, Ontario, Canada N6C 2V5
}

Correspondence should be addressed to G M Kidder; Email: gerald.kidder@schulich.uwo.ca

\begin{abstract}
Connexin43 (Cx43) is the most abundantly expressed member of the connexin (gap junction protein) family and the only one so far identified in mouse Leydig cell gap junctions. Mice lacking Cx43 were used to investigate its role in testicular androgen production and regulation. Testes from term fetuses were grafted under the kidney capsules of castrated adult males. After 3 weeks, serum from host mice was analyzed for androgens. In order to test their response to stimulation, the grafted testes were incubated in vitro with varying concentrations of $\mathrm{LH}$ and their androgen end products analyzed. Incubation with radiolabeled progesterone was followed by high performance liquid chromatography to quantify the androgen-intermediate metabolites. Radiolabeled testosterone in the presence of NADPH was used to determine the activity of testosterone-metabolizing enzymes $17 \beta$-hydroxysteroid dehydrogenase (17 $\beta \mathrm{HSD}$ ), $5 \alpha$-reductase $(5 \alpha \mathrm{R})$, and $3 \alpha$-hydroxysteroid dehydrogenase ( $3 \alpha \mathrm{HSD})$. Serum androgen levels did not differ between hosts carrying wild-type versus null mutant grafts although $\mathrm{Cx} 43$-deficient testes had more $17 \beta H S D$ and $5 \alpha \mathrm{R}$ activity than wild-type controls. Furthermore, the genotype of grafted testes did not influence LH-stimulated androgen production in vitro. These results indicate that the steroidogenic function of Leydig cells is not compromised by the absence of $\mathrm{Cx}_{43}$, perhaps because other gap junction proteins are present. Dye transfer experiments demonstrated that Cx43deficient Leydig cells retain intercellular coupling, indicating that $\mathrm{Cx} 43$ is not the only protein contributing to their gap junctions. Thus, despite their prominence in Leydig cells, $\mathrm{Cx} 43$ gap junctions are not essential for androgen production.
\end{abstract}

Reproduction (2006) 132 607-616

\section{Introduction}

Cell-cell communication mediated by gap junctions plays important roles in development and physiological function, including that of endocrine organs (Levin 2001, Serre-Beinier et al. 2002). Gap junctions are specialized regions of contact between cells where intercellular membrane channels are concentrated. Each gap junction channel is composed of two hemichannels or connexons that dock up to make a cylindrical channel, linking the cytosol of one cell with the cytosol of a neighboring cell. Each connexon is formed by the oligomerization of six protein subunits known as connexins; to date, 19 of these have been annotated in the mouse, each encoded by a distinct gene (Söhl \& Willecke 2003). Gap-junctional intercellular coupling allows cells to share low-molecular mass metabolites and second messengers that are $<1000 \mathrm{Da}$, thus facilitating homeostatic and developmental processes (Harris 2001). The focus of the present study is gap junctions in the testes.
Connexin43 (Cx43) is the most widely distributed connexin in the body and is expressed very early in development (Ruangvoravat \& Lo 1992, Yancey et al. 1992, De Sousa et al. 1993). It is the most abundant gap junction protein in the mouse testis, and so far the only one identified in Leydig cells (Perez-Armendariz et al. 1994, Varanda \& de Carvalho 1994, Bravo-Moreno et al. 2001, Risley et al. 2002). Deletion of the Gja1 gene that encodes Cx43 causes a lethal cardiac malformation: mutant fetuses develop to term but die of asphyxiation soon after birth (Reaume et al. 1995). To study postnatal testis development in the absence of this connexin, previous work utilized a graft procedure that allows gonad development to continue under the kidney capsule of an adult mouse (Kuopio et al. 1989, Roscoe et al. 2001). Grafted testes from wild-type fetuses exhibited normal development for up to 3 weeks postnatal, but those lacking $\mathrm{Cx} 43$ suffered loss of spermatogonia, resulting in a 'Sertoli cell-only' condition in the seminiferous tubules (Roscoe et al. 2001). Electron microscopical analysis of the mutant testes 
revealed cells with normal Leydig cell morphology. Furthermore, preliminary experiments indicated that luteinizing hormone (LH)-stimulated androgen production still occurred in the mutant testes, although no attempt was made to assess the cells' sensitivity to stimulation or the spectrum of androgens being produced.

Cx43 is also prominently expressed in the Leydig cells of human testes (Steger et al. 1999), making it a target of investigations aimed at understanding male infertility. Given the important roles played by $\mathrm{C} \times 43$ in the development and function of endocrine organs (Serre-Beinier et al. 2002, Klee et al. 2005), and the profound effect of its loss on spermatogenesis in the mouse (Roscoe et al. 2001), we considered it of interest to examine Cx43 null mutant Leydig cells in more detail to determine if their function had been altered.

\section{Materials and Methods}

\section{Mice}

Homozygous Cx43 knockout mice were obtained from matings of mice heterozygous for the mutant allele $\left(G j a 1^{+} / G j a 1^{-}\right)$on a CD1 background. Adult mice used as hosts for the grafted testes were $P k r d c^{\text {scid }} / P k r d c^{\text {scid }}$ males (CB17/Icr Hsd ${ }^{\text {scid; }}$; Harlan Sprague-Dawley, Indianapolis, IN, USA) that weighed 20-22 g. The mice were bred in the Department of Animal Care and Veterinary Services at the University of Western Ontario and at the Robarts Research Institute, London, ON, Canada. They were maintained and handled in accordance with the principles set forth in the Guide for Care and Use of Laboratory Animals of the Institute for Laboratory Animal Research of the National Academy of Sciences.

\section{Collection and grafting of fetal testes}

On day 17.5 of gestation, the pregnant females were anesthetized with $\mathrm{CO}_{2}$ and then killed by cervical dislocation. Fetuses were carefully dissected from the uteri, killed by decapitation, and fetal tail snips obtained. These were used for genotyping by PCR. Each tail snip was digested at $58{ }^{\circ} \mathrm{C}$ for $8-24 \mathrm{~h}$ using $100 \mu$ l proteinase $\mathrm{K}$ (Invitrogen) in buffered solution. The digested mixture was diluted in the ratio of 1:10 with Nanopure water and heated at $95{ }^{\circ} \mathrm{C}$ for $20 \mathrm{~min}$ to inactivate the proteinase $\mathrm{K}$. For each PCR, $1 \mu$ of each digest was used as a template. Details of the primers, reagents, and amplification conditions were as described previously (Roscoe et al. 2001).

The testes from each fetus were removed and placed in $0.5 \mathrm{ml} \mathrm{M199,} \mathrm{pH} 7.4$ (Invitrogen) in a Falcon Petri dish and excess tissue removed. The testes were transferred to a six-well Millicell culture plate with isopore polycarbonate membranes, $3.0 \mu \mathrm{m}$ pore size (Millipore
Canada Ltd, Nepean, ON, Canada) over M199. They were cultured at $37{ }^{\circ} \mathrm{C}$ in $5 \% \mathrm{CO}_{2}$ and were used for grafting within 2 days.

Cx43 null mutant and wild-type testes were grafted as described previously (Roscoe et al. 2001). Briefly, the host animals were anesthetized with $0.04 \mathrm{ml}$ per $10 \mathrm{~g}$ body weight of $2.5 \%$ ketamine hydrochloride (Ketaset, Ayerst Veterinary Laboratories, Guelph, ON, Canada) and $0.2 \%$ xylazine (Rompun, Bayer). The region to be incised was prepared, a lateral incision was made on the right dorsal area at the position of the kidney and the right kidney carefully exteriorized. While keeping the kidney moist at all times during the surgical procedure, a small puncture was made in the capsule and was used as an insertion point of the fetal testis. The two testes from the same fetus were grafted together but well separated to prevent them from merging and growing as one. The kidney was then slipped back into its abdominal position and the incision sutured appropriately.

\section{Gonadectomy}

For most experiments, the host male mice were left intact (i.e. not castrated) to avoid high circulating LH levels that would cause receptor desensitization. When assaying host serum for androgens, however, the host males were castrated to eliminate the contribution from the host testes. At 1 week post-grafting, the host males were anesthetized, shaved, and cleaned. The procedure was done through a small incision in the lower abdomen. The testes and the adherent fat tissue, easily seen through the aperture, were carefully exteriorized. After clamping and ligating the spermatic artery to minimize bleeding, each testis was detached and the remaining tissue returned to its abdominal location. At the same incision point, the procedure was repeated for the other testis. The incision was then sutured appropriately. After the surgical procedure, the mice were given buprenorphine analgesic $(0.3 \mathrm{mg} / \mathrm{ml}$, from Rickitt and Colman products, Hull, England, diluted in the ratio of 1:1000 with sterile water) at a dose of $0.018 \mathrm{ml} / \mathrm{g}$ body weight.

\section{Harvesting blood and grafted testes}

After 3 weeks of engraftment, the host mice were anesthetized and killed by cervical dislocation. About $800 \mu \mathrm{l}$ blood from each mouse was obtained from the heart by cardiac puncture. This was left to clot and centrifuged at $2000 \mathrm{~g}$ for $5 \mathrm{~min}$ to give $\sim 150 \mu \mathrm{l}$ serum per sample, which was used for quantification of circulating androgens by RIA. Grafted testes were retrieved by peeling them from the kidney capsule. Any adhering tissue was detached and the testes immediately placed in M199 medium. The testes were either used immediately for in vitro experimentation or fixed for histological procedures. 


\section{Leydig cell counts}

To compare Leydig cell numbers between mutant and wild-type testes, histological sections were immunostained with a polyclonal antibody raised in rabbits against human placental $3 \beta$-hydroxysteroid dehydrogenase $(3 \beta \mathrm{HSD})$, generously supplied by Dr lan Mason, University of Edinburgh. This antibody was previously shown to be specific for Leydig cells in fetal mouse testes (Doody et al. 1990). A horseradish peroxidase (HRP)- or fluorescein-conjugated secondary antibody was used to detect bound primary antibody. A standard immunostaining procedure was used. Briefly, recovered grafts were fixed in Bouin's fixative overnight and then transferred to $70 \%$ ethanol until needed. The testes were embedded in paraffin and sectioned at a thickness of $5 \mu \mathrm{m}$. The tissue sections were then deparaffinized using xylene and absolute ethanol. Slides in which an HRP-conjugated secondary antibody was to be used were then placed in $0.3 \% \mathrm{H}_{2} \mathrm{O}_{2}$ in methanol for $30 \mathrm{~min}$ to remove any endogenous peroxidase activity. All slides were rehydrated by placing them in decreasing concentrations of ethanol before washing in PBS. Immunostaining was preceded by treatment of the hydrated slides for $45 \mathrm{~min}$ with blocking solution, 2\% BSA (Life Technologies) in PBS, which was also used to dilute the primary and the secondary antibodies. The primary $3 \beta \mathrm{HSD}$ antibody (diluted in the ratio of 1:50) was placed on each slide at $4{ }^{\circ} \mathrm{C}$ overnight. Slides were then rinsed with PBS for $5 \mathrm{~min}$ before applying secondary antibody for $1 \mathrm{~h}$. A goat antirabbit secondary antibody conjugated to Alexafluor 488 (1:1000 dilution) was used for fluorescent detection and the nuclei were counterstained with Hoechst 33258 (both from Molecular Probes, Eugene, OR, USA). The slides were mounted with AIRVOL mounting medium (Airproducts and Chemicals, Allentown, PA, USA), sealed with nail polish, and observed immediately. For HRP detection, the slides were processed using a Vectastain ABC kit (Vector Laboratories, Burlingame, CA, USA) according to the manufacturers' instructions with an additional step of inhibiting endogenous peroxidase activity. HRP-conjugated goat anti-rabbit IgG (Vector Laboratories), diluted in the ratio of 1:250 and applied for $1 \mathrm{~h}$ at room temperature, was used as a secondary antibody. After washing with PBS and incubation with Vectastain for $30 \mathrm{~min}, 3,3^{\prime}$-diaminobenzidine was used to visualize the signal (FAST DAB tablets, Sigma-Aldrich, Oakville, ON, Canada). The slides were counterstained with hematoxylin and dehydrated through increasing concentrations of ethanol before mounting with Permount.

Leydig cells were quantified by counting the number of $3 \beta \mathrm{HSD}$-immunostained cells in each testis section, taking care to avoid sections in which the seminiferous tubules had been cut obliquely. The number of tubules and Leydig cells was determined for the entire testicular cross-sections. The number of Leydig cells per tubule was compared with respect to genotype.

\section{In vitro culture of testes}

In addition to grafted wild-type and mutant testes obtained from late gestation fetuses, testes from adult mice were used to validate the assays. Grafted testes were retrieved at 3 weeks post-grafting. Each testis was decapsulated and teased out to increase perfusion of culture medium into the cells before placing it in an individual well of a Millicell culture plate. Incubation was done in M199 medium buffered with $0.1 \%$ HEPES at $\mathrm{pH} 7.4$ (or $\mathrm{pH} 5$ for measurement of type II $5 \alpha$ hydroxysteroid dehydrogenase), $37{ }^{\circ} \mathrm{C}$, and $5 \% \mathrm{CO}_{2}$ and was conducted in medium alone (control) or medium plus ovine $\mathrm{LH}$ (NIH-CLH26). The distribution of androgen metabolites produced in vitro was monitored by incubating the testes with $\left[{ }^{3} \mathrm{H}\right]$ progesterone and the enzyme activities were measured by incubating with $\left[{ }^{3} \mathrm{H}\right]$ testosterone (details below). The substrate concentrations for each enzyme were maximal to ensure that the substrate was not rate limiting. The reaction was started by addition of the testes and terminated by placing the incubation on ice. The medium was harvested immediately after centrifugation at $2000 \mathrm{~g}$ for $5 \mathrm{~min}$ and stored at $-20{ }^{\circ} \mathrm{C}$ until required for assay. The testes were blotted, weighed, and stored at $-70{ }^{\circ} \mathrm{C}$ for subsequent protein assay.

The sensitivity of the Leydig cells to LH was measured by subjecting the teased out, decapsulated grafted testes from non-castrated hosts to varying concentrations of $\mathrm{LH}$ $(25-400 \mathrm{pg} / \mathrm{ml})$ in M199 medium, pH 7.4. They were incubated for $4 \mathrm{~h}$ as described previously. One grafted testis from each animal was incubated in medium alone and served as the control, while the other graft was incubated in the presence of LH. RIA was performed on the harvested medium to determine androgen accumulation in response to $\mathrm{LH}$.

\section{Radioimmunoassays}

Concentrations of circulating androgens in host blood and in culture medium were determined by RIA as described previously (Jansz \& Pomerantz 1985, Roscoe et al. 2001). The anti-testosterone antibody we used cross-reacts $98 \%$ with dihydrotestosterone, $58 \%$ with $5 \alpha$-androstane- $3 \alpha, 17 \beta$-diol, $24 \%$ with $5 \alpha$-androstane$3 \beta, 17 \beta$-diol, and negligibly $(<1.6 \%)$ with other androgens and estradiol (Jansz \& Pomerantz 1985). Diethyl ether $(2 \times 2 \mathrm{ml})$ was used for extraction of steroids from the blood serum $(60 \mu \mathrm{l})$. One hundred microliters (calculated to contain $6 \mathrm{pg}$ ) radiolabeled testosterone $\left[1,2,6,7{ }^{3} \mathrm{H}(\mathrm{N})\right]$-testosterone, specific activity 95.0 Ci/ mmol (NEN Life Science Products, Boston, MA, USA) were added to the serum before extraction and used to 
calculate steroid recovery from the samples. This was calculated at $78-82 \%$. After drying, the extracted steroids were resuspended in $60 \mu \mathrm{l}$ PBS with $0.1 \%$ gelatin (G-PBS) and used in duplicate RIA. The inter- and intra-assay coefficients of variation were 11 and $8 \%$ respectively.

\section{Androgen metabolite and steroidogenic enzyme assays}

Conversion of the radioactive substrate $[1,2,6,7,16,17$ ${ }^{3} \mathrm{H}$ ]-progesterone, specific activity $93.0 \mathrm{Ci} / \mathrm{mmol}$ (NEN Life Science Products), to various androgen intermediate metabolites was used in determining their profile. One hundred microliters (calculated to contain $0.5 \mu \mathrm{Ci}$ ) radiolabeled progesterone were added to the incubation medium. Incubation was carried out for $4 \mathrm{~h}$ in the presence of a maximally stimulating $\mathrm{LH}$ dose $(400 \mathrm{pg} / \mathrm{ml})$. The metabolites were separated and quantified by high performance liquid chromatography (HPLC) equipped with an online radioactive detector.

The activity of $5 \alpha$-reductase $(5 \alpha \mathrm{R})$ was determined by measuring conversion of $\left[{ }^{3} \mathrm{H}\right]$-testosterone (described above, $0.5 \mu \mathrm{Ci}$ ) to $\left[{ }^{3} \mathrm{H}\right] 5 \alpha$-dihydrotestosterone (DHT) and to $\left[{ }^{3} \mathrm{H}\right] 5 \alpha$-androstane- $3 \alpha, 17 \alpha$-diol together with $\left[{ }^{3} \mathrm{H}\right] 5 \alpha$-androstane $3 \alpha, 17 \beta$-diol (collectively, $3 \alpha$-diol). The incubation was for $4 \mathrm{~h}$ at $\mathrm{pH} 5$ (for type II $5 \alpha$ hydroxysteroid dehydrogenase) or $\mathrm{pH}$ 7.4. A maximally stimulating $\mathrm{LH}$ dose $(400 \mathrm{pg} / \mathrm{ml})$ and a co-factor, $2 \mathrm{mM}$ $\mathrm{NADPH}$ (Sigma-Aldrich Canada Ltd) were added to the medium. The activity of $17 \beta \mathrm{HSD}$ was determined by measuring conversion of $\left[{ }^{3} \mathrm{H}\right]$-testosterone $(0.5 \mu \mathrm{Ci})$ to $\left[{ }^{3} \mathrm{H}\right]$-androstenedione after $2 \mathrm{~h}$ of incubation at $\mathrm{pH}$ 7.4. Extraction and separation procedures were as described (Khalil \& Walton 1985).

Standard HPLC was used to identify and measure the incubation end products (Khalil \& Walton 1985). Steroids in the culture medium $(0.5 \mathrm{ml})$ were concentrated on $\mathrm{C}_{18}$ reverse-phase cartridges (Phenomenex, Torrance, CA, USA) and the steroid fraction recovered with methanol $(5 \mathrm{ml})$. A portion $(1-2 \mathrm{ml})$ of the methanol solution was dried down in a steady stream of nitrogen, and the dried down extract redissolved in $250 \mu \mathrm{l}$ mobile phase, $55 \%$ acetonitrile/water. Aliquots $(200 \mu \mathrm{l})$ of each sample were analyzed on a $\mathrm{C}_{18}$ reverse-phase column (Bondclone, $300 \times 3.9 \mathrm{~mm}$ ) with $10 \mu \mathrm{m}$ beads eluted with $55 \%$ acetonitrile/water for $30 \mathrm{~min}$ at a flow rate of $1 \mathrm{ml} / \mathrm{min}$. Radiolabeled metabolites were detected using an on-line radioactivity detector and identified on the basis of their retention times compared with authentic standards, and quantified using $\left[1,2,6,7{ }^{3} \mathrm{H}\right]$-androstenedione as external standard (Khalil \& Walton 1985). HPLC equipment consisted of a model 6000A pump, model $710 \mathrm{~B}$ automatic injectors, and a model 441 u.v. spectrophotometer, all from Waters Associates, Mississauga, ON, Canada. Radiolabeled steroid metabolites were detected and quantified by an in-line Beckman model 171 radioactivity detector (Beckman Instruments,
Toronto, ON, Canada). Data from the UV and the radioactivity detectors were analyzed by computer using the MAXIMA 820 software package from Waters Associates.

\section{Leydig cell isolation}

Leydig cell preparations were obtained as described previously with some modifications (Doody et al. 1990). Briefly, the grafted testes were retrieved from the host mice, decapsulated, and incubated with dissociation buffer at $36{ }^{\circ} \mathrm{C}$ for 15 min with agitation. The dissociation buffer consisted of M199 medium containing $0.36 \mathrm{mg} / \mathrm{ml}$ collagenase (type 1; Sigma) and $0.012 \mathrm{mg} / \mathrm{ml}$ DNase (type 1; Sigma). The enzymatic activity was terminated by placing the incubation tubes on ice and adding excess cold $\left(4{ }^{\circ} \mathrm{C}\right)$ culture medium (three volumes). The seminiferous tubules were allowed to settle by gravity for $5 \mathrm{~min}$ and the medium, containing interstitial cells, aspirated and filtered through a $70 \mu \mathrm{m}$ nylon mesh. The supernatant containing the interstitial cells was removed and centrifuged at $250 \mathrm{~g}$. The cells were washed twice and plated in $35 \times 10 \mathrm{~mm}$ tissue culture dishes (Falcon Plastics, Los Angeles, CA, USA) as $0.2 \mathrm{ml}$ aliquots in culture medium supplemented with $10 \%$ fetal bovine serum. The cells were cultured overnight at $37^{\circ} \mathrm{C}$ in a humidified atmosphere of $5 \%$ $\mathrm{CO}_{2}$ and $95 \%$ air to maintain the medium at $\mathrm{pH} 7.4$. The next day, the medium was discarded and the cells were washed with culture medium to remove loosely attached cells.

To confirm the identity of the isolated cells as Leydig cells, the cells were immunostained for $3 \beta \mathrm{HSD}$. Briefly, the plated cells were fixed for $20 \mathrm{~min}$ with $4 \%$ paraformaldehyde containing $0.1 \%$ glutaraldehyde. The cells were blocked with $2 \%$ BSA in PBS, treated with primary antibody (1:50), washed with PBS, and then treated with secondary antibody $1: 1000$ dilution of fluorescein-conjugated goat anti-rabbit IgG from ICN Biomedicals, Irvine, CA, USA). Hoechst 33342 was again used as a nuclear stain as described previously. The cells were mounted in AIRVOL, observed under phase contrast and fluorescence microscopy using a Zeiss (Thornwood, NY, USA) LSM 510 META confocal microscope mounted on an inverted Axiovert 200 motorized microscope, and photographed. Digital images were prepared using Zeiss LSM and Adobe Photoshop 7.0 software. The images were collected with a charge-coupled device (CCD) camera (Hamamatsu Photonics, Hamamatsu City, Japan) using OpenLab software (distributed by Quorum Technologies, Inc., Guelph, ON, Canada). All but a small fraction of the cells $(<10 \%)$ were positive for $3 \beta \mathrm{HSD}$ and thus the vast majority was considered to be Leydig cells. These cells were used for dye coupling assays. 


\section{Dye coupling assay}

Dye transfer assays were carried out after the Leydig cells had been cultured for $24 \mathrm{~h}$. Three milliliters of warm culture medium $\left(37^{\circ} \mathrm{C}\right)$ were added to each culture dish. A gap junction-permeant fluorescent dye, Lucifer yellow (LY; Molecular Probes) was backfilled via capillary action through a $1 \mathrm{~mm}$ thin-wall glass capillary (World Precision Instruments, Sarasota, FL, USA) pulled to $1 \mu \mathrm{m}$. The concentration of $\mathrm{LY}$ was $5 \%$ in $\mathrm{ddH}_{2} \mathrm{O}$. This was injected into a single Leydig cell and any transfer of dye to adjacent cells was observed after $2 \mathrm{~min}$. Fluorescent signals were imaged on a Zeiss inverted microscope equipped with a Sensicam CCD camera.

\section{Statistics}

Student's t-test and one-way ANOVA were followed by parametric or non-parametric tests to determine the differences between the groups. The KolmogorovSmirnov goodness-of-fit test was used to determine the need for non-parametric tests. The Mann-Whitney test was applied to determine difference due to genotype when percentage change was assessed. Significant difference between the groups was inferred at $P<0.05$.

\section{Results \\ Leydig cell numbers}

Immunostaining cross-sections of 3 week testis grafts for $3 \beta \mathrm{HSD}$ revealed that the Leydig cells in Cx43-deficient testes have an altered distribution, they are less closely clustered than those in wild-type testes (Fig. 1A and B). Although this was not quantified, it was sufficiently obvious that a blinded observer could identify the mutant testes from immunostained tissue sections. However, counts of Leydig cells (C) and seminiferous tubules (D) did not reveal any significant difference between the genotypes and, consequently, the number of Leydig cells did not differ when normalized to the number of tubules in each cross-section (Mann-Whitney test). The same result was obtained when $18.5 \mathrm{dpc}$ fetal testes were examined ( $n=8$ for each genotype, data not shown), although the difference in Leydig cell clustering was not evident at that stage. Thus, although the mutant testes are generally smaller due to the paucity of developing germ cells (Roscoe et al. 2001), the total number of Leydig cells was not affected by the mutation, either in late fetal or in juvenile stages. In both genotypes, the number of Leydig cells per seminiferous tubule did not change $(P>0.05$, Student's $t$-test) during the 3 -week grafting period.

\section{Serum androgen levels}

In the previous study of Cx43-deficient testes (Roscoe et al. 2001), incubation of grafted testes in vitro with
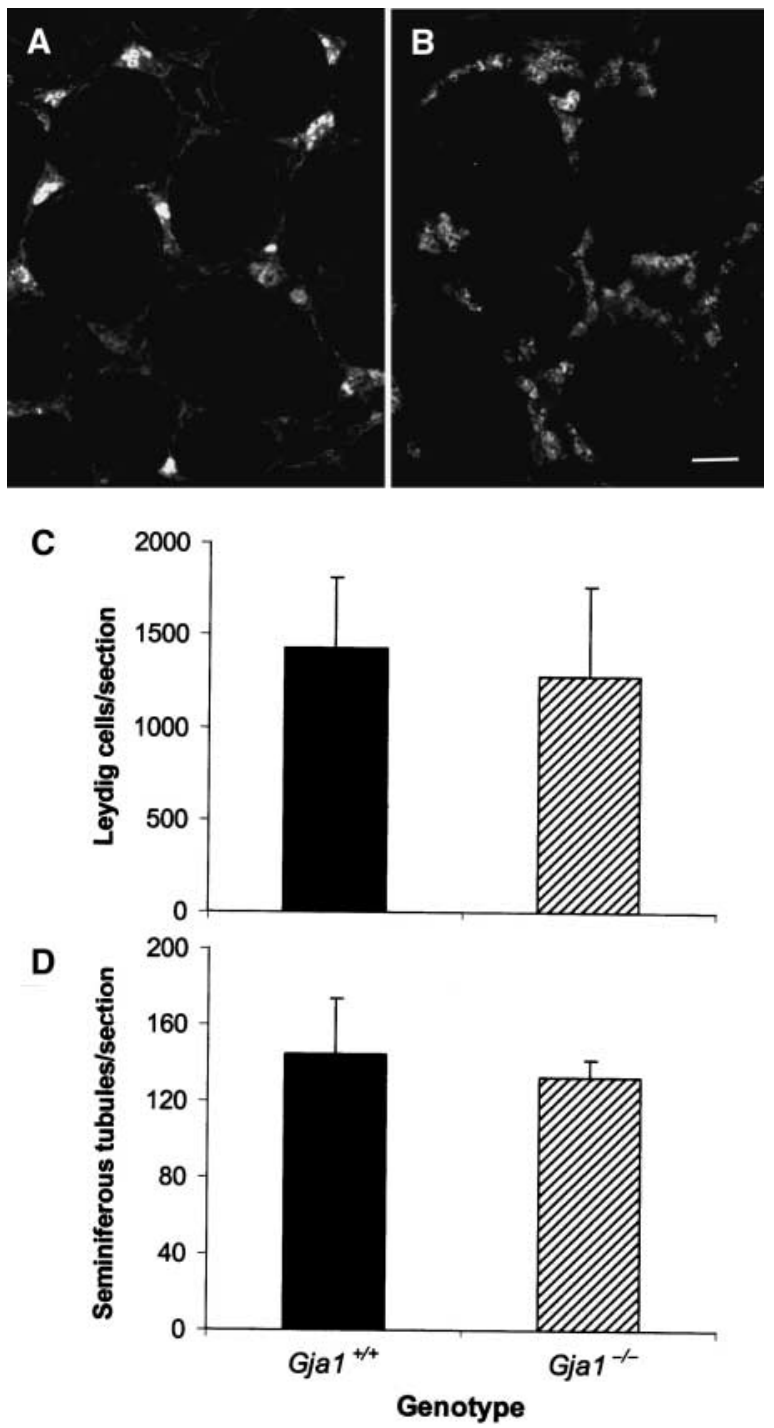

Figure 1 Spatial distribution and number of Leydig cells in grafted testes that were $\mathrm{Cx} 43$-deficient $\left(\mathrm{Gja} 1^{-/-}\right)$or wild-type $\left(\mathrm{Gja} 1^{+/+}\right)$. Leydig cells in wild-type testes (A), identified by immunostaining for $3 \beta \mathrm{HSD}$, are more tightly clustered than those in mutant testes (B). The scale bar indicates $50 \mu \mathrm{m}$. Leydig cells $(C)$ and seminiferous tubules (D) were counted in cross-sections of testes from five mice of each genotype with the values expressed as mean \pm S.E.M. The differences between the genotypes were not significant (Student's $t$-test).

a supraphysiological level of LH or cAMP revealed no difference in androgen production between mutant and wild-type grafts. To confirm this in vivo, we examined androgen production by mutant and wild-type testes in the graft hosts. Serum androgen concentrations were determined after 3 weeks of postnatal development in mice castrated 1 week after the grafting surgery (Fig. 2). Preliminary experiments verified that the 2 week period between castration of the hosts and collection of the serum samples was sufficient for the androgens produced by the host testes to have been eliminated (data not shown). The results indicated that the androgen output of 


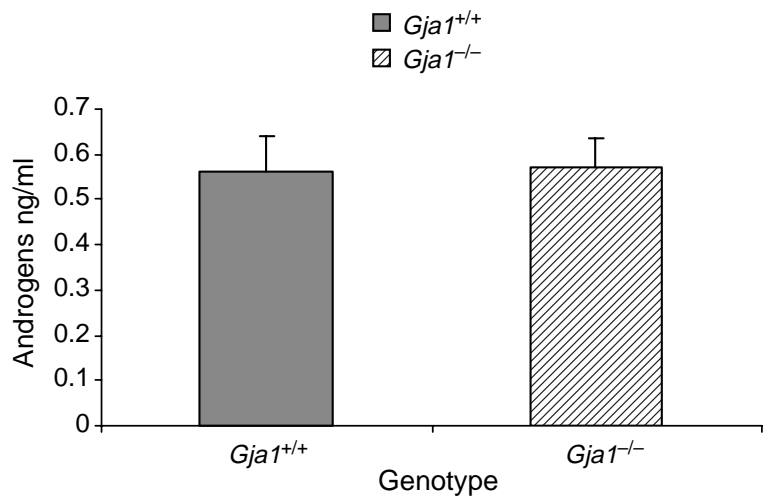

Figure 2 Serum androgen concentrations in castrated adult mice hosting grafted testes that were $\mathrm{Cx} 43$-deficient $\left(\mathrm{Gja}^{-/-}, n=16\right)$ or wild-type $\left(G j a 1^{+/+}, n=13\right)$. Serum was collected at the time of graft removal, 2 weeks after the hosts had been castrated. The values are expressed as mean \pm s.E.M. None of the differences were significant (Student's $t$-test).

the testis grafts was very low; the circulating androgen levels of the castrated, graft-bearing hosts were less than $30 \%$ of the level $(2.15 \pm 0.66 \mathrm{ng} / \mathrm{ml})$ measured in intact, ungrafted males. Importantly, androgen levels in the graft-bearing hosts did not differ between graft genotypes (Student's $t$-test). Given that the two genotypes do not differ in Leydig cell numbers (Fig. 1), the results indicate that the ability of the Leydig cells to produce testosterone was not altered by the loss of $\mathrm{C} \times 43$.

\section{LH sensitivity}

Given that gap-junctional intercellular communication has been shown to be involved in cellular responses to extracellular stimuli in several instances (Serre-Beinier et al. 2002), we wanted to determine whether the LH sensitivity of the Leydig cells had been altered by the loss of $\mathrm{Cx} 43$. On the contrary, Fig. 3 shows that the response of grafted testes to $\mathrm{LH}$ concentrations ranging between 25 and $400 \mathrm{pg} / \mathrm{ml}$ was normal; there was a significant interaction between $\mathrm{LH}$ concentration and androgen output for both genotypes (Mann-Whitney test), but there was no significant difference between the genotypes for all the LH concentrations tested (Kruskal-Wallis test). Androgen production by unstimulated testes likewise did not differ between genotypes. This indicates that Leydig cells lacking $\mathrm{Cx} 43$ are no more or less sensitive to $\mathrm{LH}$ than are wild-type Leydig cells. The LH response of adult testes was also tested (Fig. 3). The data indicate that adult and grafted juvenile testes respond to similar levels of $\mathrm{LH}$.

\section{Androgen end products}

The androgen end products released into culture medium from incubated rat or mouse testes are dependent on the stage of testicular development (Sheffield \& O'Shaughnessy 1988, Ge \& Hardy 1998).

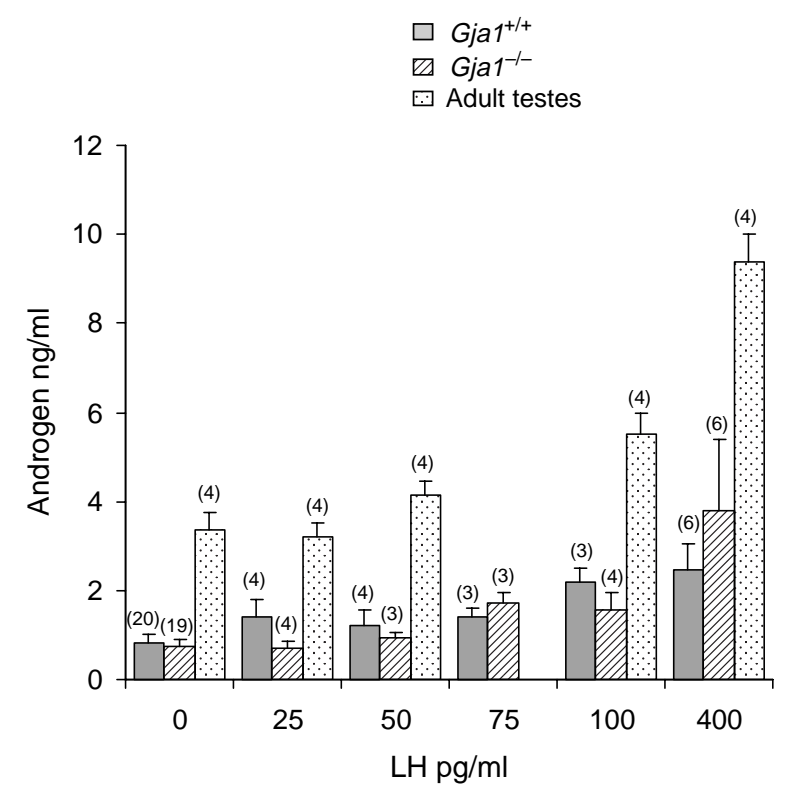

Figure $3 \mathrm{LH}$-stimulated androgen production in vitro. Fetal testes, either Cx43-deficient $\left(\mathrm{Gja}^{-/-}\right)$or wild-type $\left(\mathrm{Gja} 1^{+/+}\right)$, were grafted into intact adult hosts for 3 weeks. No significant difference was observed between the genotypes (Kruskal-Wallace test followed by Dunn's multiple comparison). Androgen output of wild-type adult testes was measured to provide a standard of comparison. The bars represent mean \pm S.E.M.; the number of testes is indicated by the number in parentheses above each bar.

In order to determine if there was a change in secreted androgen products or testicular steroidogenic enzyme activities caused by the absence of Cx43, the end products of incubation were analyzed. HPLC was used to identify and quantify the end products released by mutant and wild-type grafted testes in vitro. Figure 4 shows that the predominant product from the grafted testes was androstenedione (HPLC retention time RT= 8.77), with no quantitative difference between the mutant and the wild-type testes. Testosterone $(\mathrm{RT}=7.3)$ was also produced by all the testes, although in lower amounts. Other intermediate metabolites were either barely detectable and/or did not show consistency in the different samples, and are therefore not represented in the results. The metabolite distributions from the grafted testes were similar to the end products of 3 week-old juvenile males, although the ratio between androstenedione and testosterone was greater in the latter (Fig. 4). Although the amounts differ, the metabolite distributions affirm that the grafted testes functioned as well as nongrafted testes of an equivalent age in terms of steroidogenesis, regardless of the genotype.

\section{Steroidogenic enzyme activities}

Stage-dependent expression and activity of various enzymes involved in androgen biosynthesis and metabolism are implicated in causing variation in the major 


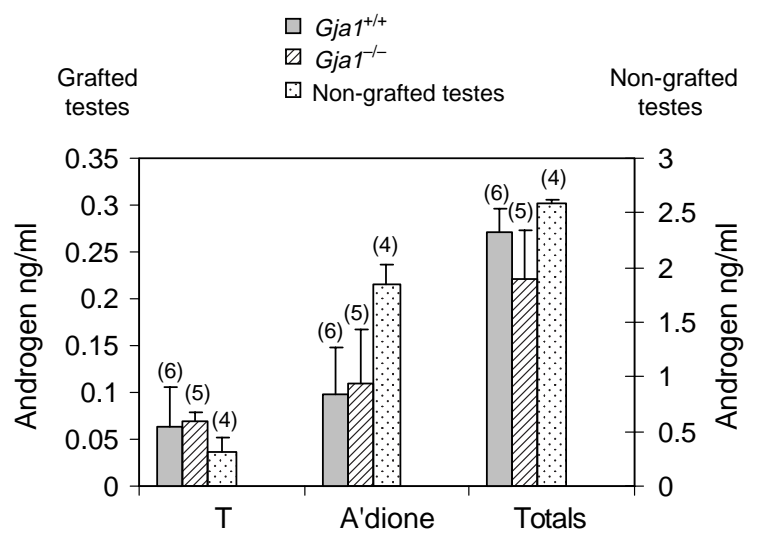

Figure 4 Analysis of androgens produced in vitro in response to $\mathrm{LH}$ $(400 \mathrm{pg} / \mathrm{ml})$. Fetal testes, either Cx43-deficient $\left(G j a 1^{-1-}\right)$ or wild-type $\left(G j a 1^{+1+}\right)$, were grafted into intact adult hosts for 3 weeks (left axis). No significant difference was observed between the genotypes (Kruskal-Wallace test followed by Dunn's multiple comparison). Wildtype testes were removed directly from 3-week-old pups and their androgen output measured to provide a standard of comparison (right axis). The bars represent mean \pm s.E.M.; the number of testes is indicated by the number in parentheses above each bar.

end products from developing testes (Ge \& Hardy 1998, O'Shaughnessy et al. 2002). There is transient expression and activity of isozymes of $17 \beta$-hydroxysteroid dehydrogenase (17 $\beta \mathrm{HSD}), 5 \alpha$-reductase $(5 \alpha \mathrm{R})$, and $3 \alpha$-hydroxysteroid dehydrogenase ( $3 \alpha \mathrm{HSD})$ involved in the metabolism of androstenedione to testosterone and the $5 \alpha$-reduced testosterone (Shan et al. 1993, Ge \& Hardy 1998, O'Shaughnessy et al. 2002). Figure 5 summarizes activity measurements for these enzymes in the grafted testes. The $3 \alpha \mathrm{HSD}$ activity was detected at very low levels in wild-type testes but not in Cx43-deficient testes. In contrast, the Cx43-deficient testes exhibited significantly greater $17 \beta \mathrm{HSD}$ and $5 \alpha \mathrm{R}$ activity. It was

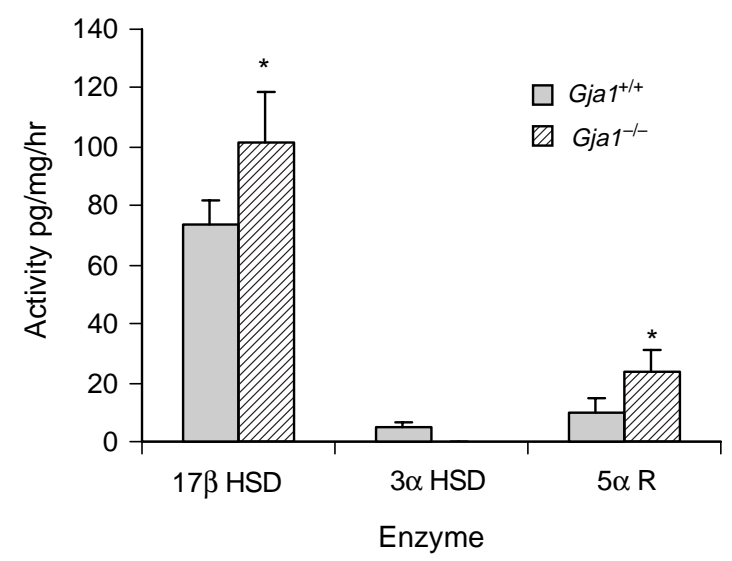

Figure 5 Activities of androgen metabolizing enzymes in Cx43deficient $\left(\mathrm{Gja}^{-/-}\right)$or wild-type $\left(G j a 1^{+/+}\right)$grafted testes. The values are expressed as mean \pm S.E.M. $(n=6)$. Activities of $17 \beta \mathrm{HSD}$ and $5 \alpha \mathrm{R}$ were significantly higher in mutant testes $(P=0.047$ and 0.045 respectively; Kruskal-Wallace test followed by Dunn's multiple comparison). $3 \alpha \mathrm{HSD}$ was not detected in mutant grafts. observed that the overall output of androgens from the grafted testes was very low. The results suggest that the grafts had not yet achieved biosynthetic characteristics of mature adult Leydig cells.

\section{Leydig cell dye coupling}

The absence of any noticeable effect of $\mathrm{Cx} 43$ deficiency on Leydig cell function could be interpreted in either of the two ways: that gap-junctional communication is not required for Leydig cell steroidogenesis, or that Leydig cells express one or more gap junction proteins in addition to $\mathrm{Cx} 43$ that can compensate for its absence. To explore the latter possibility, Leydig cells were isolated from mutant and wild-type grafted testes and their capacity to couple metabolically was assayed using a standard dye transfer test. To verify the identity of the isolated cells, they were immunostained for 3 $3 \mathrm{HSD}$ (Fig. 6). Virtually all of the cells in cultures of wild-type (Fig. 6A and B) or mutant (Fig. 6C and D) preparations stained positively for the enzyme. For cells of both genotypes, Lucifer yellow dye injection resulted in passage of the dye from the injected cell to its neighbors, indicating that Leydig cells lacking $\mathrm{C} \times 43$ retain gapjunctional communication (Fig. 6G and $\mathrm{H}$, Table 1).

\section{Discussion}

Previous work involving the grafting of Cx43-deficient testes under the kidney capsules of adult mice revealed that spermatogenesis is severely compromised by the loss of this connexin (Roscoe et al. 2001). However, that study focused on gonad size, germ cell numbers, and germ cell development, showing that spermatogonia are reduced in numbers at birth and are not able to repopulate the seminiferous tubules during postnatal development. The present work examined steroidogenesis in the mutant testes and determined that the absence of $\mathrm{Cx} 43$, while reducing the clustering of Leydig cells, does not affect their numbers or impair their functional activity.

In addition to failing to find any effect of $\mathrm{C} \times 43$ absence on Leydig cell number, our data indicated that those numbers are constant between late fetal and 3 -week juvenile stages. As indicated in previous research (Baker \& O'Shaughnessy 2001), there is very little change in Leydig cell numbers between birth and $20 \mathrm{dpp}$. This is a period during which differentiation to fetal Leydig cells is minimal and differentiation into adult Leydig cells is just beginning. In addition, it has been shown that cellular death by apoptosis does not occur in Leydig cells during the neonatal, prepubertal, pubertal, and adult periods (Faria et al. 2003). On the other hand, the distribution of Leydig cells within the interstitium differed between genotypes and between developmental stages: the difference in clustering was obvious only in 

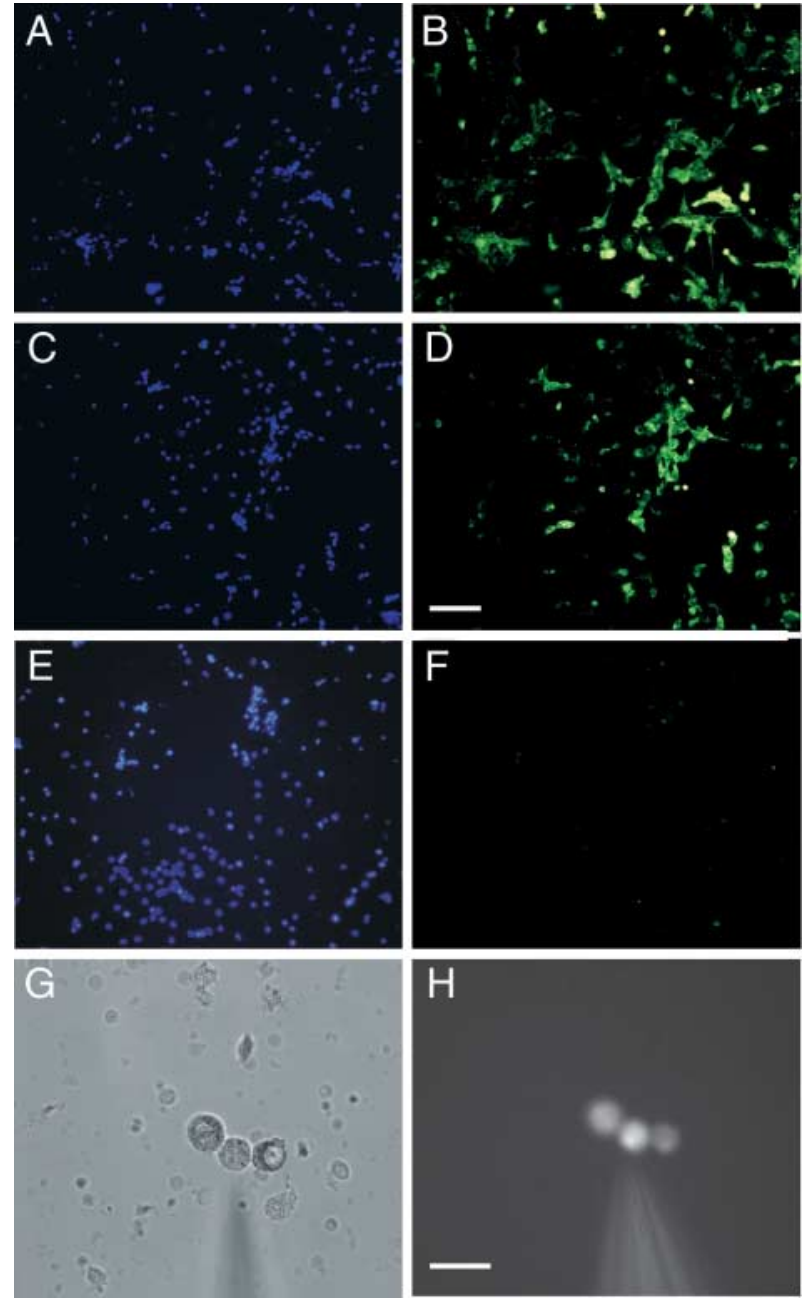

Figure 6 Confirmation of purity $(A)-(F)$ and test for dye coupling $(G)$ and $(\mathrm{H})$ among isolated Leydig cells. (A), (C) and (E) Hoechst staining for nuclei; (B), (D) and (F) immunolabeling for $3 \beta$ HSD. Positive immunostaining is shown for wild-type (A) and (B) and Cx43-deficient (C) and (D) cells but not for negative control cells (E) and (F) for which the primary antibody was omitted. The scale bar for A-F indicates $50 \mu \mathrm{m}$. (G) Bright- and (H) dark-field image showing intercellular transfer of Lucifer yellow after injection into a single Cx43-deficient Leydig cell. The scale bar for $\mathrm{G}$ and $\mathrm{H}$ indicates $25 \mu \mathrm{m}$.

the older testes. The more diffuse distribution of Leydig cells in Cx43-deficient testes could be indicative of an adhesion role for $\mathrm{Cx} 43$, which becomes prominent as testicular volume increases.

Table 1 Test for dye coupling between Leydig cells.

\begin{tabular}{lccc}
\hline Source of Leydig cells & $\begin{array}{c}\text { Total cells } \\
\text { injected }\end{array}$ & Dye transfer & $\begin{array}{c}\text { No dye } \\
\text { transfer }\end{array}$ \\
\hline $\begin{array}{l}\text { Wild-type adult testis } \\
\text { Grafted wild-type juvenile }\end{array}$ & 7 & 7 & 0 \\
$\begin{array}{l}\text { testes } \\
\begin{array}{l}\text { Grafted Cx43-deficient } \\
\text { juvenile testes }\end{array}\end{array}$ & 20 & 14 & 0 \\
\hline
\end{tabular}

In the previous study (Roscoe et al. 2001), grafted testes showed better development when the host gonads were left intact but in the present study, the host gonads were removed 1 week after the grafting procedure so that the contribution of the grafted testes to serum androgens could be determined. Our results demonstrated that the circulating levels of testosterone did not differ between hosts carrying grafts of different genotypes. Thus, gapjunctional communication among Leydig cells via Cx43 channels is not essential for androgen production.

As another test of the functional competence of $\mathrm{Cx} 43-$ deficient Leydig cells, grafted testes were recovered from their hosts and cultured in vitro with different concentrations of $\mathrm{LH}$ to determine their sensitivity to the gonadotropin. There was no significant difference in androgen production between the genotypes at any $\mathrm{LH}$ concentration. These results are in agreement with and extend previous results indicating that $\mathrm{C} \times 43$-deficient testes respond similarly to supraphysiological LH stimulation (Roscoe et al. 2001). If the in vitro results reflect the events occurring in vivo, then the mutant testes are equally responsive to $\mathrm{LH}$ as wild-type testes, even on a per-Leydig cell basis. Furthermore, we found that mutant juvenile testes respond to similar levels of $\mathrm{LH}$ as wild-type adult testes under the same assay conditions. Therefore, gap-junctional communication between Leydig cells mediated by $\mathrm{Cx} 43$ channels is not an important determinant of the cells' capacity to respond to $\mathrm{LH}$ by producing androgens.

The end products of androgen production are dependent on the maturity of the Leydig cells and can be used to assess the stage of development of those cells (Ge \& Hardy 1998, Mendis-Handagama \& Ariyaratne 2001, O'Shaughnessy et al. 2002). Testosterone is the major androgen produced by mature adult Leydig cells (mALC) in mammalian species, whereas immature adult Leydig cells (imALC), prevalent at puberty, release mainly the $5 \alpha$-reduced testosterone metabolites (Benton et al. 1995, O'Shaughnessy et al. 2002). The imALC differentiate from the newly formed adult Leydig cells (nALC) which show a predominant secretion of androstenedione. Our analysis of androgens produced by juvenile testes indicated a preferred secretion of androstenedione, which is in agreement with previous documentation of Leydig cells at this postnatal stage (O'Shaughnessy et al. 2000, Mendis-Handagama \& Ariyaratne 2001). Grafted testes retrieved at an equivalent postnatal age also showed androstenedione as the primary end product, suggesting a population not yet advanced to the pubertal stage when there should be more $5 \alpha$ reduced products of testosterone such as DHT and androstanediol. The particular androgens released from the testes depend on the balance between the synthesizing and the metabolizing enzymes. Progenitor Leydig cells show low $17 \beta \mathrm{HSD}$ and $5 \alpha \mathrm{R}$ activity but active $3 \alpha \mathrm{HSD}$ with the resultant release of androsterone as the major product (Shan et al. 1993, Ge \& Hardy 
1998, O'Shaughnessy et al. 2002). In the imALC, production of $5 \alpha$ reduced metabolites predominates due to increased expression and enzymatic activity of $5 \alpha \mathrm{R}$ and $3 \alpha \mathrm{HSD}$ with an accompanying rise in $17 \beta \mathrm{HSD}$ activity (Ge \& Hardy 1998, O'Shaughnessy et al. 2002). Our results showed relatively higher $17 \beta \mathrm{HSD}$ activity than $5 \alpha \mathrm{R}$ and $3 \alpha \mathrm{HSD}$, but overall conversion of androstenedione to testosterone and its $5 \alpha$ reduced products was very low. Hence, although there was detectable release of $3 \alpha$-diol from wild-type and juvenile testes, and DHT from the Cx43-deficient testes, the amounts did not affect the overall testosterone and androstendione levels. Likewise, the small but significant increase in $17 \beta \mathrm{HSD}$ and $5 \alpha \mathrm{R}$ activity in the mutant Leydig cells had little effect on the distribution of the different androgens. Our results consistently support the presence of some fetal Leydig cells which release androstenedione as their principal products (O'Shaughnessy et al. 2000).

Despite the fact that $\mathrm{Cx} 43$ was the only connexin known to contribute to gap junctions coupling Leydig cells, our data clearly show that Cx43-deficient Leydig cells remain dye coupled. Thus, Leydig cells may express one or more additional connexins that are yet to be identified. Furthermore, the permeability properties of that/those connexins must be sufficiently similar to those of $\mathrm{Cx} 43$ to maintain steroidogenic function in its absence. Functional overlap between members of the connexin family has been demonstrated in several instances, as has the ability of one connexin to replace another during organ development (White 2003). Another possibility is that one or more members of the recently described pannexin family of gap junction proteins might be facilitating intercellular communication between Leydig cells (Panchin etal. 2000, Bruzzone et al. 2003). Northern blot screens for pannexin expression in rat testes detected transcripts encoding pannexin1 (Baranova et al. 2004, Ray et al. 2005). However, a more complete understanding of the roles of gap-junctional intercellular communication in Leydig cell function must await identification of the additional gap junction protein(s) that contribute to the channels and the physiologically important molecules that pass through them.

\section{Acknowledgements}

The authors declare that there is no conflict of interest that would impair the impartiality of this scientific work. We are grateful to Kevin Barr for technical support and for his diligence in managing the laboratory and mouse colony, to Alfred Tran for genotyping, to the staff in the Robarts Institute Barrier Facility and the Department of Animal Care and Veterinary Services of The University of Western Ontario for their conscientious care of the mice, to Darrel Vachon for assistance with HPLC, and to Dr lan Mason for supplying the 3BHSD antibody. This work was supported by a grant from the Natural Sciences and Engineering Research Council of Canada awarded to GMK. CNK received partial stipend support from the Children's Health Research Institute, London, Ontario.

\section{References}

Baker PJ \& O'Shaughnessy PJ 2001 Role of gonadotrophins in regulating numbers of Leydig and Sertoli cells during fetal and postnatal development in mice. Reproduction 122 227-234.

Baranova A, Ivanov D, Petrash N, Pestova A, Skoblov M, Kelmanson I, Shagin D, Nazarenko S, Geraymovych E, Litvin O et al. 2004 The mammalian pannexin family is homologous to the invertebrate innexin gap junction proteins. Genomics 83 706-716.

Benton L, Shan LX \& Hardy MP 1995 Differentiation of adult Leydig cells. Journal of Steroid Biochemistry and Molecular Biology 53 61-68.

Bravo-Moreno JF, Diaz-Sanchez V, Montoya-Flores JG, Lamoyi E, Saez JC \& Perez-Armendariz EM 2001 Expression of connexin43 in mouse Leydig, Sertoli, and germinal cells at different stages of postnatal development. Anatomical Record 264 13-24.

Bruzzone R, Hormuzdi SG, Barbe MT, Herb A \& Monyer H 2003 Pannexins, a family of gap junction proteins expressed in brain. PNAS 100 13644-13649.

De Sousa PA, Valdimarsson G, Nicholson BJ \& Kidder GM 1993 Connexin trafficking and the control of gap junction assembly in mouse preimplantation embryos. Development 117 1355-1367.

Doody KM, Carr BR, Rainey WE, Byrd W, Murry BA, Strickler RC, Thomas JL \& Mason JI 19903 beta-hydroxysteroid dehydrogenase/isomerase in the fetal zone and neocortex of the human fetal adrenal gland. Endocrinology 126 2487-2492.

Faria MJ, Simoes ZL, Lunardi LO \& Hartfelder K 2003 Apoptosis process in mouse Leydig cells during postnatal development. Microscopy and Microanalysis 9 68-73.

Ge RS \& Hardy MP 1998 Variation in the end products of androgen biosynthesis and metabolism during postnatal differentiation of rat Leydig cells. Endocrinology 139 3787-3795.

Harris AL 2001 Emerging issues of connexin channels: biophysics fills the gap. Quarterly Reviews of Biophysics 34 325-472.

Jansz GF \& Pomerantz DK 1985 The effect of prenatal treatment with busulfan on in vitro androgen production by testes from rats of various ages. Canadian Journal of Physiology and Pharmacology 63 $1155-1158$.

Khalil MW \& Walton JS 1985 Identification and measurement of 4-oestren-3,17-dione (19-norandrostenedione) in porcine ovarian follicular fluid using high performance liquid chromatography and capillary gas chromatography-mass spectrometry. Journal of Endocrinology 107 375-381.

Klee P, Boucard N, Caille D, Cancela J, Charollais A, Charpantier E, Michon L, Populaire C, Peyrou M, Nlend RN et al. 2005 Connexin modulators of endocrine function.Winterhager E, ed 2005 Gap Junctions in Development and Disease 197-221.

Kuopio T, Savouras PO, Pelliniemi LJ \& Huhtaniemi IT 1989 Transplantation of newborn rat testis under the kidney capsule of adult host as a model to study the structure and function of Leydig cells. Journal of Andrology 10 335-345.

Levin M 2001 Isolation and community: a review of the role of gapjunctional communication in embryonic patterning. Journal of Membrane Biology 185 177-192.

Mendis-Handagama SM \& Ariyaratne HB 2001 Differentiation of the adult Leydig cell population in the postnatal testis. Biology of Reproduction 65 660-671.

O'Shaughnessy PJ, Baker PJ, Heikkila M, Vainio S \& McMahon AP 2000 Localization of 17beta-hydroxysteroid dehydrogenase/17ketosteroid reductase isoform expression in the developing mouse testis- androstenedione is the major androgen secreted by fetal/neonatal Leydig cells. Endocrinology 141 2631-2637.

O'Shaughnessy PJ, Willerton L \& Baker PJ 2002 Changes in Leydig cell gene expression during development in the mouse. Biology of Reproduction 66 966-975. 
Panchin Y, Kelmanson I, Matz M, Lukyanov K, Usman N \& Lukyanov S 2000 A ubiquitous family of putative gap junction molecules. Current Biology 10 R473-R474.

Perez-Armendariz EM, Romano MC, Luna J, Miranda C, Bennett MV \& Moreno AP 1994 Characterization of gap junctions between pairs of Leydig cells from mouse testis. American Journal of Physiology $\mathbf{2 6 7}$ C570-C580.

Ray A, Zoidl G, Weickert S, Wahle P \& Dermietzel R 2005 Site-specific and developmental expression of pannexin 1 in the mouse nervous system. European Journal of Neuroscience 21 3277-3290.

Reaume AG, de Sousa PA, Kulkarni S, Langille BL, Zhu D, Davies TC, Juneja SCF, Kidder GM \& Rossant J 1995 Cardiac malformation in neonatal mice lacking connexin43. Science 267 1831-1834.

Risley MS, Tan IP \& Farrell J 2002 Gap junctions with varied permeability properties establish cell-type specific communication pathways in the rat seminiferous epithelium. Biology of Reproduction 67 945-952.

Roscoe WA, Barr KJ, Mhawi AA, Pomerantz DK \& Kidder GM 2001 Failure of spermatogenesis in mice lacking connexin43. Biology of Reproduction 65 829-838.

Ruangvoravat CP \& Lo CW 1992 Connexin 43 expression in the mouse embryo: localization of transcripts within developmentally significant domains. Developmental Dynamics 194 261-281.

Serre-Beinier V, Mas C, Calabrese A, Caton D, Bauquis J, Caille D, Charollais A, Cirulli V \& Meda P 2002 Connexins and secretion. Biology of the Cell 94 477-492.
Shan LX, Phillips DM, Bardin CW \& Hardy MP 1993 Differential regulation of steroidogenic enzymes during differentiation optimizes testosterone production by adult rat Leydig cells. Endocrinology 133 2277-2283.

Sheffield JW \& O'Shaughnessy PJ 1988 Testicular steroid metabolism during development in the normal and hypogonadal mouse. Journal of Endocrinology 119 257-264.

Söhl G \& Willecke K 2003 An update on connexin genes and their nomenclature in mouse and man. Cell Communication and Adhesion 10 173-180.

Steger K, Tetens F \& Bergmann M 1999 Expression of connexin 43 in human testis. Histochemistry and Cell Biology 112 215-220.

Varanda WA \& de Carvalho AC 1994 Intercellular communication between mouse Leydig cells. American Journal of Physiology 267 C563-C569.

White TW 2003 Nonredundant gap junction functions. News in Physiological Sciences 18 95-99.

Yancey SB, Biswal S \& Revel JP 1992 Spatial and temporal patterns of distribution of the gap junction protein connexin43 during mouse gastrulation and organogenesis. Development 114 203-212.

Received 16 April 2006

First decision 5 June 2006

Revised manuscript received 14 July 2006

Accepted 10 August 2006 